\title{
Determination of the appropriate propofol infusion rate for outpatient upper gastrointestinal endoscopy-a randomized prospective study
}

\author{
Qiongzhen $\mathrm{Li}^{1 \dagger}$, Qinghe Zhou ${ }^{2+}$, Wangpin Xiao ${ }^{2}$ and Hongmei Zhou ${ }^{2 *}$
}

\begin{abstract}
Background: Pain and discomfort related to endoscopy sessions can be alleviated by sedation, which minimizes anxiety and allows safe examination. For outpatient endoscopy, reliable short-term sedation without secondary effects is required. This study aimed to assess the effects of intravenous propofol rates on sedation in outpatients undergoing upper gastrointestinal endoscopy.

Methods: This randomized prospective study evaluated 300 outpatients submitted to upper gastrointestinal endoscopy. Patients received propofol at 500, 1000 or $2000 \mathrm{ml} / \mathrm{h}$. The primary outcome assessed was hypoxemia incidence. In addition, time to sedation and incidence of hypotension, deep sedation, extremity motor activity, cough, nausea, hiccough, and awareness were evaluated.
\end{abstract}

Results: Recovery time and incidence of hypoxemia, hypotension, and deep sedation were significantly increased in individuals treated at $2000 \mathrm{ml} / \mathrm{h}$ in comparison with values obtained for 500 and $1000 \mathrm{ml} / \mathrm{h}$ groups $(P<0.01)$. Compared with the $500 \mathrm{ml} / \mathrm{h}$ group, motor activity of the extremities, cough, nausea, hiccough, and awareness were significantly decreased and the mean scores for endoscopist's and patients' satisfaction were significantly increased in the 1000 and $2000 \mathrm{ml} / \mathrm{h}$ groups $(P<0.01)$.

Conclusion: Propofol infused at $1000 \mathrm{ml} / \mathrm{h}$ appeared to be the most suitable infusion rate for outpatient upper gastrointestinal endoscopy.

Trial registration: Registration number: ChiCTR-TRC-14004786; Registration date: 2014-06-04

Keywords: Propofol, Outpatient, Upper gastrointestinal endoscopy, Sedation, Complications

\section{Background}

Pain and discomfort related to endoscopy sessions can be alleviated by sedation, which minimizes anxiety and allows safe examination [1]. Over $98 \%$ of endoscopies are performed under sedation [2, 3]. For outpatient endoscopic procedures, reliable short term sedation without secondary effects is required. Intravenous (IV) propofol is frequently used $[4,5]$.

\footnotetext{
*Correspondence: zhouhongmei120@sina.com

${ }^{\dagger}$ Equal contributors

${ }^{2}$ Department of Anesthesia, Second Hospital, Jiaxing Medical College, No.

1518, North Huancheng Road, Jianshe Street, Nanhu District, Jiaxing 314000,

Zhejiang, China

Full list of author information is available at the end of the article
}

Propofol (2, 6-diisopropylphenol) is a hypnotic agent that induces anesthesia in about $50 \mathrm{~s}$ at standard doses [6]. Propofol is characterized by short half-life, rapid onset, important volume of distribution, and absence of active metabolites, leading to rapid recovery and discharge. These properties make propofol suitable for outpatient gastrointestinal endoscopy.

Using the same dose, the final blood concentrations of propofol depend on patient sex, age and weight, and drug dose, administration rate, and cardiac output [7-10]. Previous studies have shown that the required doses for anesthesia onset are affected by changes in the rate of injection $[7,10,11]$. A previous study has shown that the hypnotic peak effect of propofol is lower using a very 
slow injection rate $(240 \mathrm{~s})$, but there was no difference when using clinically-used injection rates (5-120 s) [12]. Another study showed that the sleep dose of propofol is reduced using slower infusion rates, while fast infusion rates resulted in greater decreases in heart rate and higher incidence of apnea [13]. The use of a slow infusion rate results in longer induction duration, but requires a lower total dose, and results in a lower incidence of apnea and a lesser decrease in blood pressure [14]. However, the appropriate injection rate in an outpatient setting is still controversial.

This study aimed to identify the most suitable propofol infusion rate for outpatients submitted to upper gastrointestinal endoscopy that resulted in the lowest adverse effect incidence and was associated with the highest patient satisfaction.

\section{Methods}

\section{Study design}

This randomized, parallel, controlled study was performed at the Department of Anesthesia, Second Hospital, Jiaxing Medical College (Jiaxing, Zhejiang, China) between June 2014 and August 2014 (registration number ChiCTRTRC-14004786). The procedures were approved by the ethics review board of the Second Affiliated Hospital of Jiaxing College, chaired by Professor Liqin Jiang (number CZJ 65). Written informed consent was obtained from each patient prior to participation.

\section{Patients}

For patient inclusion, the following criteria were set: 1) American Society of Anesthesiologists (ASA) class I-III; 2) upper gastrointestinal endoscopy; and 3) age 18-65 years. Exclusion criteria were: 1) pregnancy; 2) allergies to eggs, beans, or latex; 3 ) history of alcohol or sedative overdose [15]; 4) history of adverse events associated with propofol; 5) sleep apnea or acute gastrointestinal hemorrhage; or 6) recent abnormalities of the central nervous system such as stroke.

\section{Intervention}

The patients were randomized to one of three groups using a random number table. Patients were administered oxygen at a rate of $2-3 \mathrm{~L} / \mathrm{min}$ using a nasal catheter before induction. Propofol (Xi'an Libang Shaanxi, China; batch number: 1405282) was administered as an IV bolus by a sub-senior anesthesiologist (13 years of experience) at $500(500 \mathrm{ml} / \mathrm{h}$ group $), 1000(1000 \mathrm{ml} / \mathrm{h}$ group $)$ or $2000 \mathrm{ml} / \mathrm{h}(2000 \mathrm{ml} / \mathrm{h}$ group$)$ to unconsciousness. Upon loss of consciousness, rapid infusion was stopped. If the patient still had body movements after infusion, an additional $20-30 \mathrm{mg}$ of propofol was administered to avoid body movements during the procedure. The same senior endoscopist (18 years of experience) performed all procedures with the help of the same supervisor nurse (15 years of experience). The endoscopist had no access to grouping information. The anesthesiologist that administered the additional propofol was blinded to patient's history and initial induction infusion rate.

The target depth of sedation was loss of consciousness, no response to call, and eyelashes reflection. At this moment, propofol was stopped and the endoscope was inserted. If the patients had a body response upon endoscope insertion, propofol was added. The depth of sedation was evaluated according to body response and bispectral index (BIS) values.

\section{Monitoring}

An arm vein of the patient was intubated with a $22 \mathrm{G}$ infusion catheter, and non-invasive monitoring of the arterial pressure was performed with the contralateral arm. Heart, respiratory, and oxygen saturation $\left(\mathrm{SpO}_{2}\right)$ rates were continuously monitored. Induction dose corresponded to the drug amount delivered, and the rate was recorded (Smiths WZ-50F6 two-way injection pump; Zhejiang Smith Medical Instruments Co., Ltd., Ningxia, China). Any excitatory effects or periods of apnea ( $>30 \mathrm{~s})$ after induction were recorded. Recovery time reflected the period from endoscopy end to full orientation (the patient was able to provide his/her correct date of birth).

The level of sedation was evaluated using BIS monitoring [16-18]. After skin disinfection, disposable electrodes were placed on the forehead, with the leads connected to a BIS Aspect monitor (Medical System, USA), whose output was assessed throughout the operation and recovery. BIS $\leq 65,66-85$, and $>85$ indicated deep, conscious, and mild sedation states, respectively. BIS levels were recorded at the following times: baseline, loss of consciousness, endoscope reaching the glottis, endoscope reaching the duodenum, end of endoscopy, and recovery. An independent observer (resident doctor, 3 years of experience, blind to grouping) was responsible for monitoring the patients including level of consciousness and adverse reactions (hypoxemia, bradycardia, hypotension, body movements, cough, nausea, hiccough, awareness) and for data collection (drugs, doses, and onset of cardiorespiratory events).

Adverse events were: hypoxemia (hypoxemia was defined $\mathrm{SpO} 2$ falling below $90 \%$ ), hypotension (systolic or diastolic blood pressure values decreasing by $20 \%$ or more) and bradycardia (heart rate less than $50 \mathrm{bpm}$ ). Severe hypoxemia was defined as $\mathrm{SpO} 2$ declining below $90 \%$, while mild hypoxemia was defined as $\mathrm{SpO} 2$ declining below $90 \%$ but rising to above $90 \%$ after more than $30 \mathrm{~s}$ of jaw thrust maneuver. 
As described by Cohen [19], we compared the three groups with respect to the time to induction (time period from first drug bolus dose to procedure initiation) and the time to recovery (time elapsed from endoscope removal to final evaluation). A patient was discharged only when BIS levels exceeded 90 and when there was no complaint of pain or discomfort.

At hospital discharge, a 10-point visual analogue scale (VAS) was used to evaluate patient satisfaction, from 1 to 10 , representing least and most satisfied, respectively. Additionally, a VAS was used by the endoscopist to record his level of satisfaction with the sedation regimen. Respondents had to circle the number that corresponded the best to their experience. The endoscopist's VAS was scored as $1-3,4-7$, and 8-10 for considerable, minor, and no difficulty in performing the procedure; respectively.

\section{Data collection}

Age, sex, weight, height, ASA physical status, complications and adverse reactions during endoscopy, patient VAS score, and endoscopist VAS score were recorded. The following parameters were recorded during endoscopy: time to unconsciousness, total propofol dose, propofol dose $\left(\mathrm{mg} \cdot \mathrm{kg}^{-1}\right)$, duration of endoscopy, recovery time, and BIS value at baseline, loss of consciousness, endoscope reaching the glottis, endoscope reaching the duodenum, end of endoscopy and recovery.

\section{Endpoints}

The primary endpoint was the incidence of hypoxemia. The secondary endpoints were: incidence of adverse events other than hypoxemia (bradycardia, hypotension, body movement, cough, nausea, hiccough and, awareness); satisfaction of the endoscopist with sedation; BIS values; time to loss of consciousness; total propofol dose; pain during injection; endoscopy duration; and recovery time.

\section{Statistical analysis}

Based on our preliminary experiments, the mean frequency of hypoxemia (primary outcome) was approximately $12 \%$ during gastrointestinal endoscopy, and the sample size was calculated based on reducing this frequency by $50 \%$. To achieve $90 \%$ power at an $\alpha$ level of 0.05 to detect a twotailed difference, at least 88 patients were required in each group.

Data were analyzed using SPSS 19.0 (IBM, Armonk, NY, USA). Continuous data are mean \pm standard deviation (SD). Categorical data were reported as frequencies. Oneway analysis of variance (ANOVA) was employed for group comparisons, with the post hoc Bonferroni multiple comparison test. Categorical variables were assessed by the Pearson's chi-square test. Two-tailed $P$-value $\leq 0.05$ was considered statistically significant. Statistical review of this study was performed by a biomedical statistician (Tao Zhu).

\section{Results}

\section{Characteristics of the patients}

A total of 368 individuals were enrolled, with 41 not meeting the inclusion criteria; 18 withdrew from the study and 9 were excluded for unknown reasons. All patients underwent endoscopy for diagnostic procedures. The remaining 300 patients were randomized into one of the three groups (Fig. 1). Table 1 presents the characteristics of the patients. Patients were aged 50.1 \pm 13.1 , $52.0 \pm 11.3$ and $51.0 \pm 11.3$ years in the 500, 1000 and $2000 \mathrm{ml} / \mathrm{h}$ groups, respectively, and the proportion of females was 68.4, 72.2 and $64.3 \%$, respectively (all $P>0.05$ ). There was no difference in weight, height, ASA class, body mass index (BMI), and endoscopy history (all $P>0.05)$.

\section{Time to loss of conscious, dose, duration of endoscopy, and recovery time}

Time to loss of consciousness was significantly longer with the slower infusion rates $(86.4 \pm 6.0$ vs. $54.1 \pm 4.8$ vs. $32.4 \pm 5.2 \mathrm{~s}$ at 500,1000 and $2000 \mathrm{ml} / \mathrm{h}$, respectively; all $P<0.01$ ). Total (induction dose + eventual additional doses) and weight-related induction doses were significantly less with 500 and $1000 \mathrm{ml} / \mathrm{h}$ compared with $2000 \mathrm{ml} / \mathrm{h}$ $(2.4 \pm 0.4$ and $2.4 \pm 0.3$ vs. $2.9 \pm 0.5 \mathrm{mg} / \mathrm{kg}, P<0.01)$. In comparison with patients treated at $500 \mathrm{ml} / \mathrm{h}$, the duration of endoscopy was decreased in the 1000 and $2000 \mathrm{ml} / \mathrm{h}$ groups $(P<0.05)$. However, in comparison with individuals treated with propofol at $2000 \mathrm{ml} / \mathrm{h}$, recovery times were shorter in the 500 and $1000 \mathrm{ml} / \mathrm{h}$ groups $(18.1 \pm 2.0 \mathrm{vs}$. $13.2 \pm 1.6$ and $13.1 \pm 1.6 \mathrm{~min}, P<0.05$ ) (Table 2 ).

\section{Bispectral index values}

Compared with the 500 and $1000 \mathrm{ml} / \mathrm{h}$ groups, BIS values were significantly decreased in patients receiving propofol at $2000 \mathrm{ml} / \mathrm{h}$ at loss of consciousness, endoscope reaching the glottis, endoscope reaching the duodenum and end of endoscopy $(P<0.01)$ (Table 3$)$.

\section{Complications and adverse reactions}

In comparison with the $2000 \mathrm{ml} / \mathrm{h}$ group, the frequencies of hypotension and hypoxemia were significantly decreased in patients administered propofol at 500 and $1000 \mathrm{ml} / \mathrm{h}$ $(P<0.01)$. However, no statistically significant differences were obtained between groups regarding arrhythmia and pain during injection (Tables 4 and 5). Compared with the 1000 and $2000 \mathrm{ml} / \mathrm{h}$ groups, the frequencies of extremity motor activity, cough, nausea, hiccough and awareness were significantly increased in patients treated at $500 \mathrm{ml} / \mathrm{h}$ $(P<0.01)$ (Table 4$)$. Deep sedation rate was significantly increased after propofol administration at $2000 \mathrm{ml} / \mathrm{h}$ 


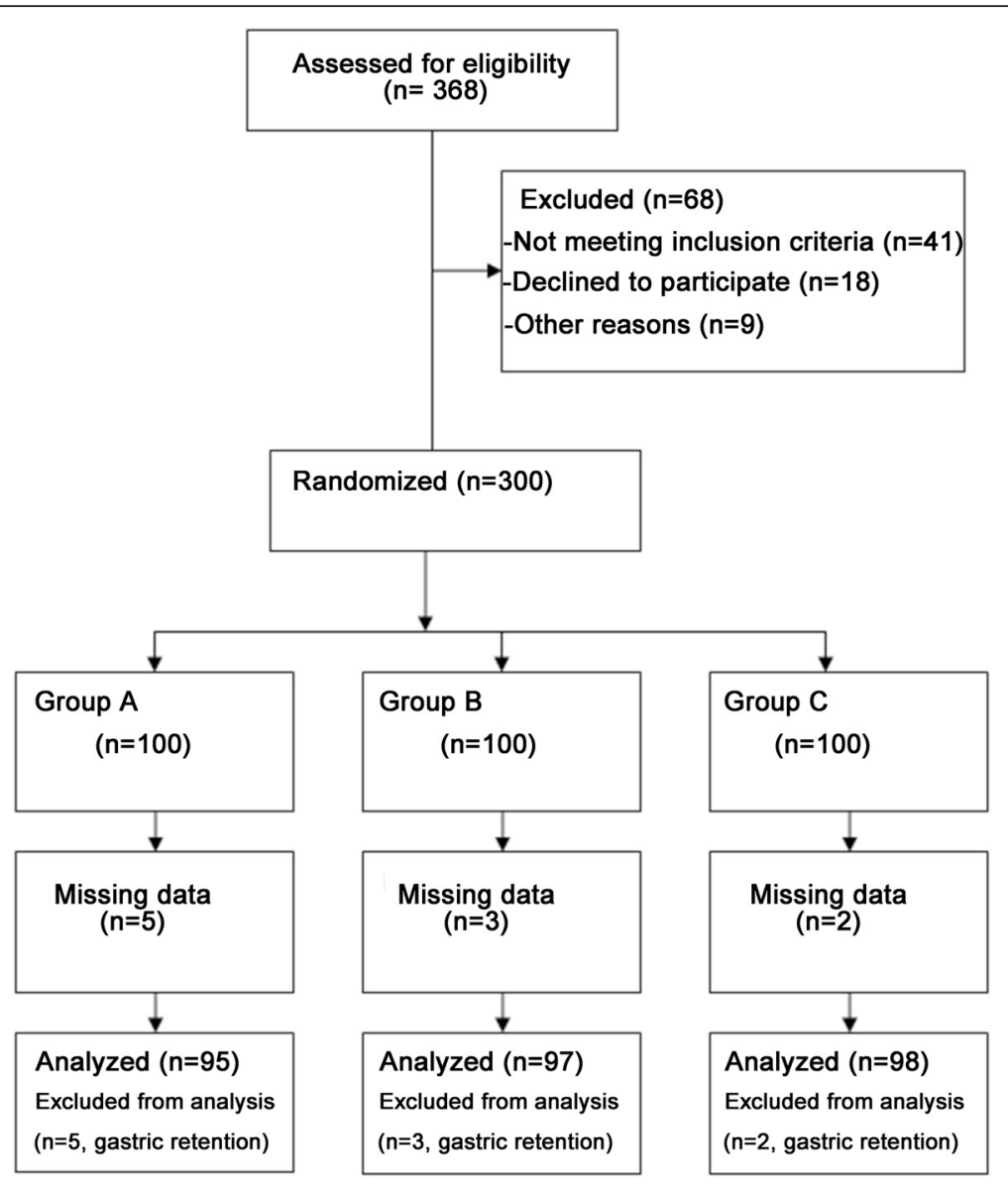

Fig. 1 Patient flowchart

compared with the 500 and $1000 \mathrm{ml} / \mathrm{h}$ groups $(P<0.01)$

(Table 4).

\section{Satisfaction}

Mean VAS scores were significantly decreased in patients treated with propofol at $500 \mathrm{ml} / \mathrm{h}$ in comparison with those receiving the drug at $1000 \mathrm{ml} / \mathrm{h}(P<0.01)$ and $2000 \mathrm{ml} / \mathrm{h}(P<0.05)$. Average VAS scores for endoscopist's satisfaction were significantly increased in the 1000 and $2000 \mathrm{ml} / \mathrm{h}$ groups compared with the $500 \mathrm{ml} / \mathrm{h}$ group $(P<0.01)$ (Table 5$)$.

\section{Discussion}

This study aimed to assess three infusion rates of propofol for their impact on sedation and adverse effects for outpatient upper gastrointestinal endoscopy. Results showed that the incidences of hypoxemia, hypotension, and deep sedation and the recovery times were significantly increased in patients treated at $2000 \mathrm{ml} / \mathrm{h}$ in comparison with the 500 and $1000 \mathrm{ml} / \mathrm{h}$ groups. Compared with the $500 \mathrm{ml} / \mathrm{h}$ group, motor activity of the extremities, cough, nausea, hiccough, and awareness were significantly decreased and the mean scores on the visual analogue scale for endoscopist's and

Table 1 Characteristics of the patients

\begin{tabular}{lllll}
\hline Variables & $500 \mathrm{ml} / \mathrm{h}(n=95)$ & $1000 \mathrm{ml} / \mathrm{h}(n=97)$ & $2000 \mathrm{ml} / \mathrm{h}(n=98)$ & $P 1 \pm 11.3$ \\
\hline Age (years) & $50.1 \pm 13.1$ & $52 \pm 11.3$ & $63 / 35$ & $>0.05$ \\
Sex $(\mathrm{M} / \mathrm{F})$ & $65 / 30$ & $70 / 27$ & $61.9 \pm 8.8$ & $>0.05$ \\
Weight $(\mathrm{kg})$ & $63.6 \pm 11.7$ & $62.5 \pm 8.1$ & $161.6 \pm 6.7$ & $>0.05$ \\
Height $(\mathrm{cm})$ & $162.7 \pm 7.1$ & $161.9 \pm 6.6$ & $58 / 34 / 6$ & $>0.05$ \\
ASA class I/II/II & $60 / 30 / 5$ & $63 / 26 / 8$ & $3 / 3$ & $>0.05$ \\
BMI $<16$ or BMI $>30\left(\mathrm{~kg} \mathrm{~m}^{-2}\right)$ & $2 / 5$ & $1 / 2$ & 70 & $>0.05$ \\
Endoscopy history & 65 & 72 & & $>0.05$
\end{tabular}

Data are expressed as means \pm SD or number of patients. ASA American Society of Anesthesiologists 
Table 2 Time to loss of consciousness, dosage, duration of endoscopy, and recovery time

\begin{tabular}{lccc}
\hline Variables & $500 \mathrm{ml} / \mathrm{h}$ & $1000 \mathrm{ml} / \mathrm{h}$ & $2000 \mathrm{ml} / \mathrm{h}$ \\
\hline Time to loss of consciousness & $86.4 \pm 6.0$ & $54.1 \pm 4.8^{*}$ & $32.4 \pm 5.2^{* * * *}$ \\
Total propofol dose (induction dose + additional doses) $(\mathrm{mg})$ & $155.1 \pm 15.4$ & $150.8 \pm 12.1$ & $180.1 \pm 19.5^{* * * *}$ \\
Propofol dose $\left(\mathrm{mg}^{*} \mathrm{~kg}^{-1}\right)$ & $2.4 \pm 0.4$ & $2.4 \pm 0.3$ & $2.9 \pm 0.5^{* * * *}$ \\
Duration of endoscopy $(\mathrm{min})$ & $4.0 \pm 0.6$ & $3.4 \pm 0.6^{*}$ & $3.5 \pm 0.6^{*}$ \\
Recovery times $(\mathrm{min})$ & $13.2 \pm 1.6$ & $13.1 \pm 1.6$ & $18.1 \pm 2.0^{* * * *}$ \\
\hline
\end{tabular}

Data are expressed as means \pm SD

$* P<0.01$ vs. $500 \mathrm{ml} / \mathrm{h}$

${ }^{* *} P<0.01$ vs. $1000 \mathrm{ml} / \mathrm{h}$

patients' satisfaction were significantly increased in the 1000 and $2000 \mathrm{ml} / \mathrm{h}$ groups.

Here, BIS was used as a new way to assess deep sedation frequency. To improve the sensitivity and specificity, deep sedation was defined as BIS $\leq 65[16-18,20]$. Based on this definition, deep sedation occurred in 18, 16 and $51 \%$ of the patients in the 500, 1000 and $2000 \mathrm{ml} / \mathrm{h}$ groups, respectively. Although propofol was administered at rates targeting conscious sedation, deep sedation was often obtained at $2000 \mathrm{ml} / \mathrm{h}$. However, it should be noted that BIS monitoring accuracy for detecting deep sedation is still controversial [17]. Differences in BIS values were observed between the groups at loss of consciousness, endoscope reaching the glottis, endoscope reaching the duodenum and the end of endoscopy. In addition, a greater decrease in BIS was observed after treatment at $2000 \mathrm{ml} / \mathrm{h}$ in comparison with the 500 and $1000 \mathrm{ml} / \mathrm{h}$ groups. Prior to these time points, BIS values were similar between the three groups. Therefore, it may be assumed that these differences might result from the propofol dose used for induction $\left(2.9 \mathrm{mg} \mathrm{kg}^{-1}\right.$ ) during procedure initiation. The BIS recordings are reflective of the previous $15 \mathrm{~s}$ of brain activity [18], and BIS values exhibit good correlation with consciousness [9]. Deep sedation associated adverse effects were readily alleviated with common clinical procedures. Although brain propofol amounts were not measured here, the delay from infusion completion and complete response suppression in the $2000 \mathrm{ml} / \mathrm{h}$ group might corroborate findings in sheep by Ludbrook et al. [21]. Our method eliminated spuriously

Table 3 Bispectral index value at different time points

\begin{tabular}{llll}
\hline Time points & $500 \mathrm{ml} / \mathrm{h}$ & $1000 \mathrm{ml} / \mathrm{h}$ & $2000 \mathrm{ml} / \mathrm{h}$ \\
\hline Baseline & $96.0 \pm 1.7$ & $96.5 \pm 1.5$ & $96.1 \pm 1.8$ \\
Loss of consciousness & $80.0 \pm 3.8$ & $79.1 \pm 3.7$ & $75.9 \pm 4.0^{* * * *}$ \\
Endoscope reaching the glottis & $75.8 \pm 3.9$ & $74.9 \pm 3.5$ & $69.0 \pm 2.7^{* * * *}$ \\
$\begin{array}{l}\text { Endoscope reaching the } \\
\text { duodenum }\end{array}$ & $67.0 \pm 2.9$ & $68.0 \pm 3.0$ & $62.9 \pm 4.5^{* * * *}$ \\
End of endoscopy & $71.2 \pm 5.6$ & $72.0 \pm 5.4$ & $67.8 \pm 3.1^{* * *}$ \\
Recovery & $87.6 \pm 1.5$ & $87.8 \pm 1.5$ & $87.5 \pm 1.5$ \\
\hline
\end{tabular}

Data are expressed as means \pm SD

$* P<0.01$ vs. $500 \mathrm{ml} / \mathrm{h}$

${ }^{* *} P<0.01$ vs. $1000 \mathrm{ml} / \mathrm{h}$ high BIS scores that arise from patient stimulation during modified observer's assessment of alertness/sedation (MOAA/S) scale evaluation. By frequently stimulating the patient for MOAA/S, the sedation target might require more medication and a higher MOAA/S score than if the MOAA/S score were assessed less frequently. The drug dose and sedation depth were similar when the two methods were used [22]. In the present study, the patients were evaluated, and the drugs were adjusted according to BIS rather than MOAA/S score. BIS is superior to $\mathrm{MOAA} / \mathrm{S}$ in simplicity, offering more continuous measurements. It therefore objectively evaluate sedation in individuals submitted to endoscopy [16].

Low infusion rates in the $500 \mathrm{ml} / \mathrm{h}$ group did not abolish patient reflexes although eyelids remained closed, which probably led to the difference in endoscopy duration since less movements results in an easier procedure. Our findings indicate that increased propofol infusion rate is associated with decreased BIS values, in agreement with previous studies [20, 23]. Insufficient propofol administration results in patient excitement, and additional propofol must be given for endotracheal intubation. Therefore, there is a need for proper anesthetic amounts during endoscopy, prior to the procedure. Slow induction is more likely to cause excitatory side effects. In the present study,

Table 4 Complications and adverse reactions during endoscopy

\begin{tabular}{llll}
\hline $\begin{array}{l}\text { Complications and } \\
\text { adverse reactions }\end{array}$ & $500 \mathrm{ml} / \mathrm{h}$ & $1000 \mathrm{ml} / \mathrm{h}$ & $2000 \mathrm{ml} / \mathrm{h}$ \\
\hline Hypoxemia & $10(10.5)$ & $15(15.4)$ & $40(40.8)^{* *^{*}}$ \\
Arrhythmia & $0(0.0)$ & $1(1.0)$ & $3(3.1)$ \\
Systolic hypotension & $10(10.5)$ & $14(14.4)$ & $30(30.6)^{* * *}$ \\
Diastolic hypotension & $16(16.8)$ & $19(19.6)$ & $45(45.9)^{* * * *}$ \\
Extremity motor activity & $33(34.7)$ & $9(9.3)^{*}$ & $7(7.1)^{*}$ \\
Cough & $16(16.8)$ & $5(5.2)^{*}$ & $2(2.0)^{*}$ \\
Nausea & $19(20.0)$ & $7(7.2)^{*}$ & $4(4.1)^{*}$ \\
Hiccough & $15(15.8)$ & $4(4.1)^{*}$ & $3(3.1)^{*}$ \\
Awareness & $17(17.9)$ & $2(2.1)^{*}$ & $1(1.0)^{*}$ \\
Deep sedation & $18(18.9)$ & $16(16.5)$ & $51(52.0)^{* * * *}$ \\
\hline
\end{tabular}

Data are expressed as number (\%)

${ }^{*} P<0.01$ vs. $500 \mathrm{ml} / \mathrm{h}$

${ }^{* *} P<0.01$ vs. $1000 \mathrm{ml} / \mathrm{h}$ 
Table 5 Pain during injection and satisfaction

\begin{tabular}{llll}
\hline Variable & $500 \mathrm{ml} / \mathrm{h}$ & $1000 \mathrm{ml} / \mathrm{h}$ & $2000 \mathrm{ml} / \mathrm{h}$ \\
\hline Pain during injection & $7(7.4)$ & $10(10.3)$ & $9(9.2)$ \\
Patients' VAS & $9.5 \pm 0.6$ & $9.8 \pm 0.4^{*}$ & $9.7 \pm 0.5^{* *}$ \\
Endoscopist's VAS & $8.0 \pm 0.8$ & $9.3 \pm 0.9^{*}$ & $9.4 \pm 0.8^{*}$
\end{tabular}

Data are expressed as means \pm SD or number (\%)

${ }^{*} P<0.01$ vs. $500 \mathrm{ml} / \mathrm{h}$

${ }^{* * P}<<0.05$ vs. $1000 \mathrm{ml} / \mathrm{h}$

deeper anesthesia was achieved with faster injection, as indicated by the loss of the eyelash reflex.

Fanti et al. [24] have reported that the most common complications in gastrointestinal endoscopy were related to the sedation and not to the procedure itself. These complications include cardio-respiratory adverse events such as hypoxemia, hypoventilation, apnea, dysrhythmias, hypotension and vasovagal episodes [24]. As shown above, no differences in heart rates among the three groups were observed.

Hypoxemia incidence rates were 10,15 and $40 \%$ in the $500 \mathrm{ml} / \mathrm{h}, 1000 \mathrm{ml} / \mathrm{h}$ and $2000 \mathrm{ml} / \mathrm{h}$ groups, respectively, making it the most common complication. However, hypoxemia responded to oxygen supplementation. Relatively high transient mild hypoxemia rates in all groups might result from the close patient monitoring during sedation. Such data contribute to fueling the debate on the routine administration of supplemental oxygen during upper gastrointestinal endoscopy. The overall incidence of apnea was $22.4 \%$ as shown above, in agreement with previous studies (20-30\%) $[25,26]$ assessing younger subjects with apnea defined as a ventilatory pause $>40 \mathrm{~s}$.

Mild hypotension is a frequent complication of propofol sedation. The reduction in hypotension frequency in the 500 and $1000 \mathrm{ml} / \mathrm{h}$ groups compared with the $2000 \mathrm{ml} / \mathrm{h}$ group is consistent with the results of previous studies [7-10, 12-14, 27]. This mild hypotension rarely has adverse clinical consequences and usually requires no intervention. The hypotensive episodes in the present study were transient and did not require pharmacological treatment.

Studies have demonstrated that a slower propofol injection rate decreases cardiovascular effects ([12-14, 28, 29]. However, slow injection rates might result in longer induction times $[12-14,30]$. As shown above, increased induction times were observed with lower injection speeds, corroborating previous studies [12-14, 30, 31]. Here, lower infusion rates caused increased induction times, resulting in reduced induction doses of propofol, without differences in the total propofol dose at induction end. Propofol was administered at $2.4 \mathrm{mg} / \mathrm{kg}$ in average at 500 and $1000 \mathrm{ml} / \mathrm{h}$, which is in the standard range of $2-2.5 \mathrm{mg} / \mathrm{kg}$ [32].
This study has some potential limitations. First, the patients were exclusively Chinese individuals, and some conclusions might not be globally generalized. Second, we did not evaluate the economics or the side effects of the regimens after the patients were discharged. Third, all patients received oxygen before induction, and the controversy about routine oxygen administration [33, 34] could not be addressed by the present study. Fourth, men and women were included, and it is well known that there are gender differences in anesthesia [35]. Fifth, different levels of sedation depth could be associated different rates of adverse effects, which could confound the results. Sixth, only mild/moderate sedation was studied, and the results may not apply to deep sedation. Seventh, no cost-effectiveness analysis was performed, but it may be assumes that optimizing the sedation process should lead to decrease costs. Eighth, some patients had a history of endoscopy, which could influence their experience of subsequent procedures. Finally, we did not follow-up the patients after discharge to monitor eventual longer-term adverse effects.

The present study suggests that a propofol infusion rate of $1000 \mathrm{ml} / \mathrm{h}$ appears to be the most appropriate rate for upper gastrointestinal endoscopy anesthesia, resulting in fewer adverse effects and improved satisfaction. Therefore, this rate should be used for upper gastrointestinal endoscopy anesthesia in selected patients corresponding to the inclusion criteria of this study. These results suggests that it is possible to optimize propofol administration in these patients. Nevertheless, further studies are necessary to broaden the generalisability of these results.

\section{Conclusion}

In conclusion, a propofol infusion rate of $1000 \mathrm{ml} / \mathrm{h}$ appears to be the most appropriate rate for upper gastrointestinal endoscopy anesthesia. This rate resulted in fewer complications and adverse reactions during endoscopy, as well as in improved endoscopist satisfaction.

\section{Data availability}

Data are available upon request to the corresponding author.

\section{Abbreviations \\ IV: intravenous; VAS: visual analogue scale.}

Competing interests

The authors declare that they have no competing interests.

\section{Authors' contributions}

QZL, QHZ and HMZ contributed to conception and design; QZL, QHZ, WPX and $\mathrm{HMZ}$ contributed to acquisition of data, or analysis and interpretation of data; QZL, QHZ and HMZ have been involved in drafting the manuscript or revising it critically for important intellectual content; all authors have given final approval of the version to be published. 


\section{Acknowledgements}

This work was supported by the Second Affiliated Hospital of Jiaxing College, Jiaxing, China. The authors thank the nurses in the recovery room and the gastroscopy department for their help in observing the study subjects and collecting the data.

\section{Author details}

'Department of Anesthesia, Shanghai Chest Hospital, Shanghai Jiao Tong University, Shanghai, China. 'Department of Anesthesia, Second Hospital, Jiaxing Medical College, No. 1518, North Huancheng Road, Jianshe Street, Nanhu District, Jiaxing 314000, Zhejiang, China.

Received: 1 December 2015 Accepted: 9 April 2016 Published online: 26 April 2016

\section{References}

1. Lichtenstein DR, Jagannath S, Baron TH, Anderson MA, Banerjee S, Dominitz JA, et al. Standards of Practice Committee of the American Society for Gastrointestinal, Endoscopy. Sedation and anesthesia in Gl endoscopy. Gastrointest Endosc. 2008;68:815-26.

2. McQuaid KR, Laine L. A systematic review and meta-analysis of randomized, controlled trials of moderate sedation for routine endoscopic procedures. Gastrointest Endosc. 2008;67:910-23.

3. Cohen LB, Wecsler JS, Gaetano JN, Benson AA, Miller KM, Durkalski V, et al. Endoscopic sedation in the United States: results from a nationwide survey. Am J Gastroenterol. 2006;101:967-74.

4. Dumonceau JM, Riphaus A, Aparicio JR, Beilenhoff U, Knape JT, Ortmann M, et al. European Society of Gastrointestinal Endoscopy, European Society of Gastroenterology and Endoscopy Nurses and Associates, and the European Society of Anaesthesiology Guideline: Non-anaesthesiologist administration of propofol for Gl endoscopy. Eur J Anaesthesiol. 2010;27:1016-30.

5. Liu SY, Poon CM, Leung TL, Wong CW, Chan YL, Leung TC, et al. Nurseadministered propofol-alfentanil sedation using a patient-controlled analgesia pump compared with opioid-benzodiazepine sedation for outpatient colonoscopy. Endoscopy. 2009;41:522-8.

6. Coll-Vinent B, Sala X, Fernandez C, Bragulat E, Espinosa G, Miro O, et al. Sedation for cardioversion in the emergency department: analysis of effectiveness in four protocols. Ann Emerg Med. 2003;42:767-72.

7. Kazama T, Ikeda K, Morita K, Ikeda T, Kikura M, Sato S. Relation between initial blood distribution volume and propofol induction dose requirement. Anesthesiology. 2001;94:205-10.

8. Kazama T, Ikeda K, Morita K, Kikura M, Ikeda T, Kurita T, et al. Investigation of effective anesthesia induction doses using a wide range of infusion rates with undiluted and diluted propofol. Anesthesiology. 2000;92:1017-28.

9. Adachi $\mathrm{YU}$, Higuchi $\mathrm{H}$. Prediction of propofol induction dose using multiple regression analysis. Anesthesiology. 2002;96:518-9.

10. Adachi $\mathrm{YU}$, Watanabe $\mathrm{K}$, Higuchi $\mathrm{H}$, Satoh $\mathrm{T}$. The determinants of propofol induction of anesthesia dose. Anesth Analg. 2001:92:656-61.

11. Rolly G, Versichelen L, Zubair NA. Use of ICl 35868 as an anesthetic induction agent. Acta Anaesthesiol Belg. 1980;31:241-7.

12. Blum J, Kochs E, Forster N, Schneider $G$. The influence of injection rate on the hypnotic effect of propofol during anesthesia: a randomized trial. PLoS Clin Trials. 2006;1:e17.

13. Stokes DN, Hutton P. Rate-dependent induction phenomena with propofol: implications for the relative potency of intravenous anesthetics. Anesth Analg. 1991;72:578-83.

14. Peacock JE, Lewis RP, Reilly CS, Nimmo WS. Effect of different rates of infusion of propofol for induction of anaesthesia in elderly patients. $\mathrm{Br}$ J Anaesth. 1990;65:346-52.

15. Santos ME L d, Maluf-Filho F, Chaves DM, Matuguma SE, Ide E, Luz Gde O, et al. Deep sedation during gastrointestinal endoscopy: propofol-fentanyl and midazolam-fentanyl regimens. World J Gastroenterol. 2013;19:3439-46.

16. Moses PL, Vargo JJ, Mitty RD, Pleskow DK, Walker JA, Rex DK. BIS values correlate with clinical sedation scores during midazolam/narcotic or propofol sedation for endoscopy. Gastrointest Endosc. 2004;59:P130.

17. Qadeer MA, Vargo JJ, Patel S, Dumot JA, Lopez AR, Trolli PA, et al. Bispectral index monitoring of conscious sedation with the combination of meperidine and midazolam during endoscopy. Clin Gastroenterol Hepatol. 2008;6:102-8.

18. Johansen JW. Update on bispectral index monitoring. Best Pract Res Clin Anaesthesiol. 2006;20:81-99.
19. Cohen LB, Hightower CD, Wood DA, Miller KM, Aisenberg J. Moderate level sedation during endoscopy: a prospective study using low-dose propofol, meperidine/fentanyl, and midazolam. Gastrointest Endosc. 2004;59:795-803.

20. Gale T, Leslie K, Kluger M. Propofol anaesthesia via target controlled infusion or manually controlled infusion: effects on the bispectral index as a measure of anaesthetic depth. Anaesth Intensive Care. 2001;29:579-84.

21. Ludbrook GL, Upton RN, Grant C, Martinez A. The effect of rate of administration on brain concentrations of propofol in sheep. Anesth Analg. 1998:86:1301-6.

22. Miner JR, Danahy M, Moch A, Biros M. Randomized clinical trial of etomidate versus propofol for procedural sedation in the emergency department. Ann Emerg Med. 2007;49:15-22.

23. Rudner R, Jalowiecki P, Kawecki P, Gonciarz M, Mularczyk A, Petelenz M. Conscious analgesia/sedation with remifentanil and propofol versus total intravenous anesthesia with fentanyl, midazolam, and propofol for outpatient colonoscopy. Gastrointest Endosc. 2003;57:657-63.

24. Fanti $\mathrm{L}$, Testoni PA. Sedation and analgesia in gastrointestinal endoscopy: what's new? World J Gastroenterol. 2010;16:2451-7.

25. Sanderson JH, Blades JF. Multicentre study of propofol in day case surgery. Anaesthesia. 1988:43(Suppl):70-3.

26. Redfem N, Srafford MA, Brooker J, Hull CJ. Incremental propofol for minor gynaecological procedures. Postgrad Med J. 1985;61:127-8.

27. Claeys MA, Gepts E, Camu F. Haemodynamic changes during anaesthesia induced and maintained with propofol. Br J Anaesth. 1988:60:3-9.

28. Kanto J, Gepts E. Pharmacokinetic implications for the clinical use of propofol. Clin Pharmacokinet. 1989:17:308-26.

29. Wagner BK, Berman SL, Devitt PA, O'Hara DA. Retrospective analysis of postoperative nausea and vomiting to determine antiemetic activity of droperidol added to propofol: a possible drug interaction. Pharmacotherapy. 1994;14:586-91.

30. Rolly G, Versichelen L, Huyghe L, Mungroop H. Effect of speed of injection on induction of anaesthesia using propofol. Br J Anaesth. 1985;57:743-6.

31. Gillies GW, Lees NW. The effects of speed of injection on induction with propofol. A comparison with etomidate. Anaesthesia. 1989;44:386-8.

32. Cummings GC, Dixon J, Kay NH, Windsor JP, Major E, Morgan M, et al. Dose requirements of $\mathrm{ICl} 35,868$ (propofol, 'Diprivan') in a new formulation for induction of anaesthesia. Anaesthesia. 1984:39:1168-71.

33. Zed PJ, Abu-Laban RB, Chan WW, Harrison DW. Efficacy, safety and patient satisfaction of propofol for procedural sedation and analgesia in the emergency department: a prospective study. CJEM. 2007:9:421-7.

34. Tohda G, Higashi S, Wakahara S, Morikawa M, Sakumoto H, Kane T. Propofo sedation during endoscopic procedures: safe and effective administration by registered nurses supervised by endoscopists. Endoscopy. 2006:38:360-7.

35. Pleym $\mathrm{H}$, Spigset $\mathrm{O}$, Kharasch ED, Dale $\mathrm{O}$. Gender differences in drug effects: implications for anesthesiologists. Acta Anaesthesiol Scand. 2003;47:241-59.

\section{Submit your next manuscript to BioMed Central and we will help you at every step:}

- We accept pre-submission inquiries

- Our selector tool helps you to find the most relevant journal

- We provide round the clock customer support

- Convenient online submission

- Thorough peer review

- Inclusion in PubMed and all major indexing services

- Maximum visibility for your research

Submit your manuscript at www.biomedcentral.com/submit 